\title{
A BBO/PSO based Hybrid Technique for Distribution System Feeder Reconfiguration
}

\author{
Kothuri Ramakrishna, Basavaraja Banakara
}

\begin{abstract}
A cooperative strategy to reconfigure the feeder network by maximizing the location and volume of the distribution generator $(D G)$ in the power system was addressed in this report. The new feature of the proposed method is the integrated output of the Biography Based Optimization (BBO) and PSO techniques. The above methods are the optimization techniques used to configure the radial distribution system for the optimal position and capacities of the DG. For determining the optimum position and strength of the $D G$, the $B B O$ algorithm includes radial distribution network voltage, actual and reactive energy. The input parameters of $\mathrm{BBO}$ are classified into sub settings here and are allowed as the optimization of the PSO algorithm. The PSO synthesizes the problem and uses sub-parameters to create the sub-solution. The method of BBO migration and mutation is used to determine the optimal position and ability of DG for the sub solution of PSO. The cooperative strategy introduced is then applied on the system MATLAB / Simulink, and the usefulness is evaluated using $B B O$ and PSO techniques. The findings of the analysis demonstrate the strength of the solution suggested and affirm its capacity for resolving the problem.
\end{abstract}

Keywords: PSO, BBO, DG, Feeder

\section{INTRODUCTION}

L ately, Distributed Generations (DGs) usually tend to become joining a significant reason in Electrical Distribution Systems (EDS) as a result of eco-friendly concerns, gas cost unpredictability's together with liberalization linked with power market places [1] DGs often tend to become small generating tools in between lots of KWs for you to 100 MWs: small, tiny, channel and also significant DGs, which are actually suited at the lots establishments to undermine electrical power deficiencies in addition to inabilities [2] Contrasted to substantial principal power station based upon nonrenewable fuel source, oil, together with gas-fired vegetations [3], DGs sources for example wind electrical generators, photovoltaic or pv, energy mobiles, biomass, mini electrical generators, tiny hydroelectric plant, garbage

Revised Manuscript Received on December 30, 2019.

* Correspondence Author

Kothuri Ramakrishna*, Department of Electrical and Electronics Engineering, Jawaharlal Nehru Technological University Hyderabad (JNTUH), Hyderabad, Telangana. Email: engineer.krk9@gmail.com

Basavaraja Banakara, Professor E \& E, Registrar Evaluation, Davanagere University, Davangere, Karnataka. Email: banakara36@gmail.com

(C) The Authors. Published by Blue Eyes Intelligence Engineering and Sciences Publication (BEIESP). This is an open access article under the CC BY-NC-ND license (http://creativecommons.org/licenses/by-nc-nd/4.0/) dump fuel, and so forth. [4] acquire a lessened volume of funds expense in addition to servicing and also maintenance expenses, the location is actually a whole lot less complicated to obtain as well as have a lot less bad impact the environments [5] The significant trait conveniences which is actually readily available coming from DGs often tend to become development connected with current security \& current profile page, electrical power reduction lowering, exceptional unit reliability \& security together with boosted energy high quality (PQ) \& company related to extra answers [6-7] It is actually likewise quite handy in lowering it result rate. DGs could be taken advantage of probably in a split up technique or maybe in a bundled method. Therefore, it can easily provide in the places where the core creation could be unwise and even no matter where you can easily discover insufficiencies in the genuine transferring procedure [8-9]

Within EDS, DGs could aid planned for in theory as well as monetarily because, they have the capacity to post onement associated with gear box as well as circulation collections upgrade projects [10] DGs possess a sizable impact on the electrical power action, current account, security, constancy, degree, as well as premium associated with energy wanted for customers and also power customers. The real setup gotten in touch with DGs might potentially well to network device operation, nevertheless a lot of quantity or perhaps sizes associated with DGs effective could create infractions in the approach limits That is actually why, the proper measurements and also positioning associated with circulated wind turbines are actually important aimed for optimum advantage in the electric energy unit. In case DG items usually tend to become included on non-optimal places, the electrical power shortages enhance, triggering high expenditure of electrical power, current boost by the end of your farmer, require source unbalance within a shortcoming condition, electric energy excellent quality reduce as well as reduce pertaining to integrity variations.

A shared strategy has actually been actually reviewed in this particular newspaper for area as well as the ability of circulation power generator (DG) in energy body. The uniqueness of the suggested strategy is actually the bundled efficiency of both the Biography Based optimization (BBO) as well as Particle Swarm Optimization (PSO) procedures. The stated procedures are actually the optimization strategies, which are actually utilized for maximizing the ideal place as well as ability of the DG for branched organization system. The BBO protocol calls for branched ordering system current, sensitive as well as actual electrical power for identifying the optimal place and also capability of the DG. 


\section{A BBO/PSO based Hybrid Technique for Distribution System Feeder Reconfiguration}

Listed below, the BBO input criteria are actually categorized in to below specifications and also made it possible for as the PSO formula optimization method. The PSO formation the trouble as well as establishes the below service with help from below criteria. The BBO transfer and also anomaly method is actually requested the below remedy of PSO for pinpointing the ideal area as well as capability of DG.

\section{PROposed BBO/PSO HybRID TECHNIQUe}

The recommended reciprocal procedure possesses the bundled function of both the BBO protocol and also PSO protocol. The pointed-out strategies are actually the optimization approaches, which are actually made use of for improving the maximum area as well as capability of the DG for branched ordering system. The BBO formula calls for branched organization system current, responsive as well as genuine electrical power for the maximum area and also capability of the DG. Below, the input specifications are actually divided right into below criteria as well as enabled as the PSO formula. The PSO formation the issue as well as creates the below service with help from below criteria. The BBO transfer as well as anomaly procedure is actually requested the below service of PSO as well as recognize the ideal area and also capability of DG. The finest remedy is actually settled coming from each strategy end results. The measures to recognize the maximum area and also ability of DG for branched ordering system are actually illustrated in the observing Flow Chart.

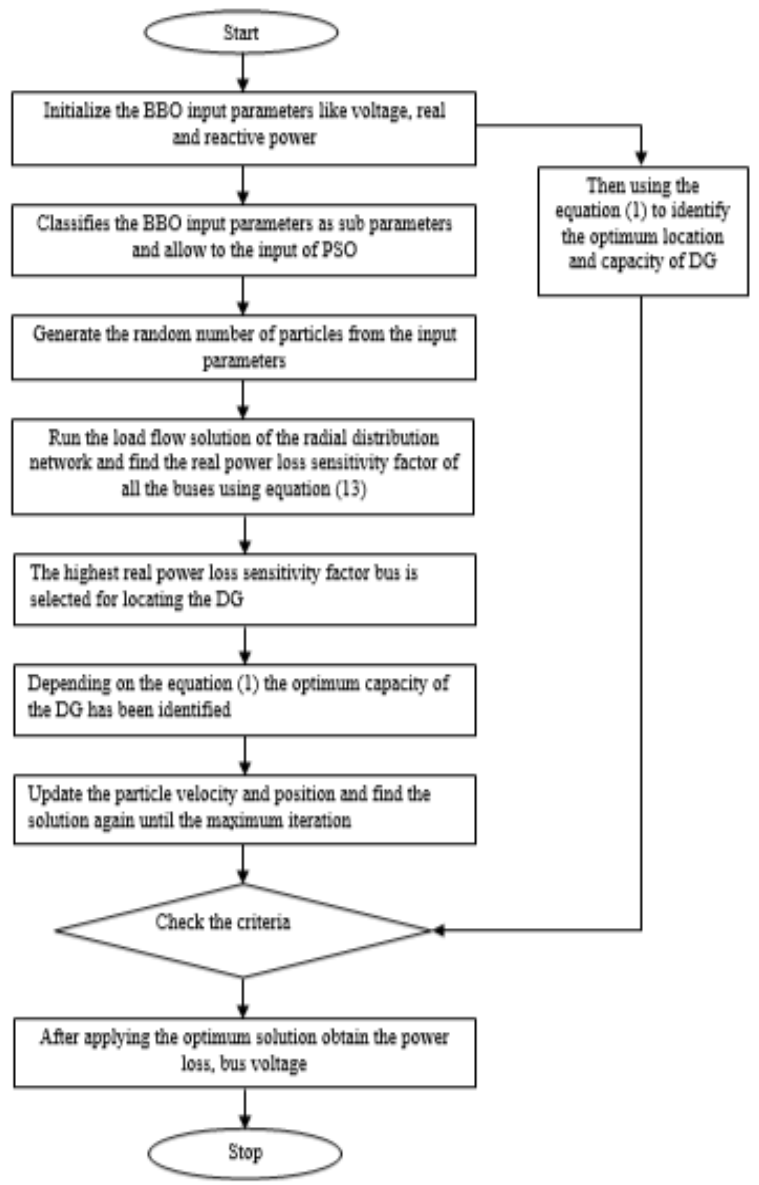

Fig: 1 Flow chart of the Proposed Mutual Algorithm

\section{RESULTS AND DISCUSSIONS:}

This area illustrates the planned approach verification utilizing the designed technique. Below, the evaluated circulation unit design is actually received amount 2 , through which thirty-three nodules, 32 divisions. The examinations are actually executed in the p.u body along with $12.66 \mathrm{kV}$ and also 100MVA. The IEEE thirty-three bus branched circulation device construct is actually explained in the observing body 3. Listed here, the IEEE thirty-three bus branched circulation device current, energy reduction assessments are actually performed due to the recommended technique. The going along with location indicates the connection examination has actually made use of varied type of instances.

Case 1: Without reconfiguration of the bus system and DG units

Case 2: Optimally reconfigured bus system by the available sectionalizing and tie switches.

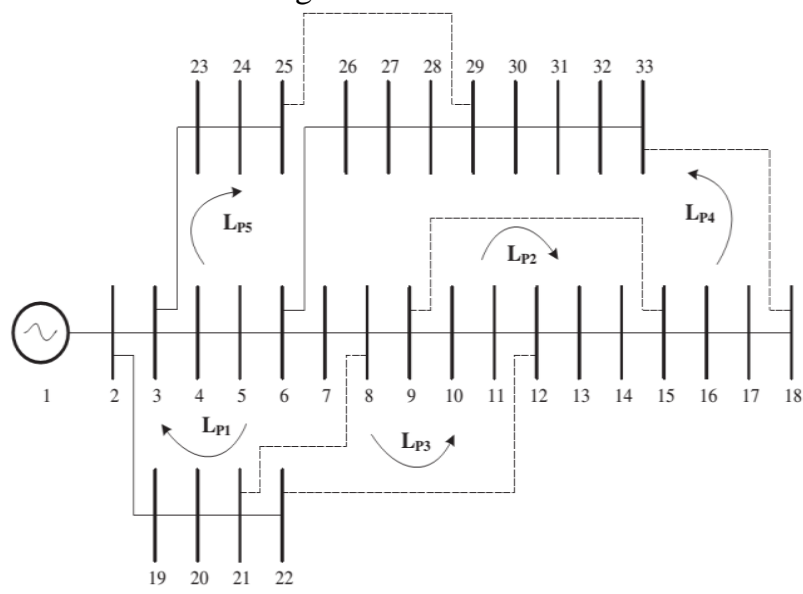

Fig 2: IEEE 33 bus system for Distribution system feeder reconfiguration

Table.1: System voltage profile analysis using proposed method for different load levels

\begin{tabular}{|c|c|c|c|c|}
\hline \multirow{2}{*}{$\begin{array}{c}\text { Scena } \\
\text { rio }\end{array}$} & \multirow{2}{*}{ Item } & \multicolumn{3}{|c|}{ Load type } \\
\hline & & Type 1 & Type 2 & $\begin{array}{c}\text { Type } \\
3\end{array}$ \\
\hline \multirow{3}{*}{$\begin{array}{c}\text { Case } \\
1\end{array}$} & $\begin{array}{c}\text { Switche } \\
\text { s } \\
\text { opened }\end{array}$ & $\begin{array}{c}3-14-24- \\
27-30\end{array}$ & $\begin{array}{c}10-3-6-2 \\
1-15\end{array}$ & $\begin{array}{c}12-27 \\
-14-6 \\
-9 \\
\end{array}$ \\
\hline & $\begin{array}{c}\mathrm{V}_{\text {worst }} \\
\text { (bus no) }\end{array}$ & $\begin{array}{c}0.8955 \\
(18) \\
\text { Best } \\
0.9965\end{array}$ & $\begin{array}{c}0.8955 \\
(18) \\
\text { Best-0.99 } \\
63\end{array}$ & $\begin{array}{c}0.894 \\
6(18) \\
\text { Best- } \\
0.996 \\
4 \\
\end{array}$ \\
\hline & $\begin{array}{c}\mathrm{V}_{\text {best }} \\
\text { (bus no) }\end{array}$ & $0.9966(2)$ & $0.9966(2)$ & $\begin{array}{c}0.996 \\
8(2) \\
\end{array}$ \\
\hline \multirow{3}{*}{$\begin{array}{c}\text { Case } \\
2\end{array}$} & $\begin{array}{c}\text { Switche } \\
\text { s } \\
\text { opened }\end{array}$ & $\begin{array}{c}2-13-8-32 \\
-18\end{array}$ & $\begin{array}{c}12-12-10- \\
11-14\end{array}$ & $\begin{array}{c}18-17 \\
-16-9- \\
17 \\
\end{array}$ \\
\hline & $\begin{array}{c}\mathrm{V}_{\text {worst }} \\
\text { (bus no) }\end{array}$ & $\begin{array}{c}0.8940 \\
(17) \\
\text { Best } \\
-0.9971 \\
\end{array}$ & $\begin{array}{c}0.8947 \\
(17) \\
\text { Best-0.99 } \\
63 \\
\end{array}$ & $\begin{array}{l}0.899 \\
8(16)\end{array}$ \\
\hline & $\begin{array}{c}\mathrm{V}_{\text {best }} \\
\text { (bus no) }\end{array}$ & $0.9964(2)$ & & $\begin{array}{c}0.996 \\
4(2) \\
\end{array}$ \\
\hline
\end{tabular}


Table.2: Voltage profile comparison for different type of load levels

\begin{tabular}{|c|c|c|c|c|}
\hline \multirow[t]{2}{*}{ Scenario } & \multirow[t]{2}{*}{ Item } & \multicolumn{3}{|c|}{ Solution techniques } \\
\hline & & Proposed & BBO & PSO \\
\hline \multirow{4}{*}{ Type 1} & $\begin{array}{c}\text { Switches } \\
\text { opened }\end{array}$ & $\begin{array}{c}7-32-30- \\
18-3\end{array}$ & $\begin{array}{c}32-30-9 \\
-11-25\end{array}$ & $\begin{array}{l}2-4- \\
24-2 \\
7-10\end{array}$ \\
\hline & $\begin{array}{c}\mathrm{V}_{\text {worst }} \\
\text { (bus no) }\end{array}$ & $\begin{array}{c}0.8970 \\
(17)\end{array}$ & $\begin{array}{c}0.9271 \\
(18)\end{array}$ & $\begin{array}{c}0.91 \\
31 \\
(18)\end{array}$ \\
\hline & $\begin{array}{c}\mathrm{V}_{\text {best }} \\
\text { (bus no) }\end{array}$ & $\begin{array}{c}0.9965 \\
(2)\end{array}$ & $\begin{array}{c}0.9965 \\
(2)\end{array}$ & $\begin{array}{c}0.99 \\
15 \\
(2)\end{array}$ \\
\hline & $\begin{array}{l}\text { DG size } \\
\text { (bus no) }\end{array}$ & $\begin{array}{c}99.769 \\
(32)\end{array}$ & $\begin{array}{c}100.559 \\
(26)\end{array}$ & $\begin{array}{c}112 . \\
651 \\
(4)\end{array}$ \\
\hline \multirow{4}{*}{ Type 2} & $\begin{array}{c}\text { Switches } \\
\text { opened }\end{array}$ & $\begin{array}{c}26-2-16- \\
22-17\end{array}$ & $\begin{array}{l}27-32-2 \\
3-30-31\end{array}$ & $\begin{array}{l}\text { 3-4- } \\
10-2 \\
8-20\end{array}$ \\
\hline & $\begin{array}{c}\mathrm{V}_{\text {worst }} \\
\text { (bus no) }\end{array}$ & $\begin{array}{c}0.8955 \\
(18)\end{array}$ & $\begin{array}{c}0.9145 \\
(17)\end{array}$ & $\begin{array}{c}0.90 \\
13 \\
(32) \\
\end{array}$ \\
\hline & $\begin{array}{c}\mathrm{V}_{\text {best }} \\
\text { (bus no) }\end{array}$ & $\begin{array}{c}0.9796 \\
(3)\end{array}$ & $\begin{array}{c}0.9965 \\
(2)\end{array}$ & $\begin{array}{c}0.98 \\
75 \\
(2)\end{array}$ \\
\hline & $\begin{array}{l}\text { DG size } \\
\text { (bus no) }\end{array}$ & $\begin{array}{c}70.435 \\
(8)\end{array}$ & $\begin{array}{c}96.399 \\
\text { (3) }\end{array}$ & $\begin{array}{c}105 . \\
365 \\
(6)\end{array}$ \\
\hline \multirow{4}{*}{ Type 3} & $\begin{array}{l}\text { Switches } \\
\text { opened }\end{array}$ & $\begin{array}{c}31-31-6- \\
17-17\end{array}$ & $\begin{array}{c}13-23-5 \\
-6-9\end{array}$ & $\begin{array}{c}5-7- \\
10-1 \\
8-9\end{array}$ \\
\hline & $\begin{array}{c}\mathrm{V}_{\text {worst }} \\
\text { (bus no) }\end{array}$ & $\begin{array}{c}0.9050 \\
(33)\end{array}$ & $\begin{array}{c}0.9199 \\
(33)\end{array}$ & $\begin{array}{c}0.89 \\
88 \\
(17)\end{array}$ \\
\hline & $\begin{array}{c}\mathrm{V}_{\text {best }} \\
\text { (bus no) }\end{array}$ & $\begin{array}{c}0.9964 \\
(2)\end{array}$ & $\begin{array}{c}0.9975 \\
(2)\end{array}$ & $\begin{array}{c}0.98 \\
85 \\
(19)\end{array}$ \\
\hline & $\begin{array}{l}\text { DG size } \\
\text { (bus no) }\end{array}$ & $\begin{array}{c}103.524 \\
(25)\end{array}$ & $\begin{array}{c}105.477 \\
(17)\end{array}$ & $\begin{array}{c}118 . \\
787 \\
(5)\end{array}$ \\
\hline
\end{tabular}

Table.3: System power loss analysis using proposed method for different load levels

\begin{tabular}{|c|c|c|c|c|}
\hline Scenario & Item & \multicolumn{2}{|c|}{ Solution techniques } \\
\cline { 3 - 5 } & & $\begin{array}{c}\text { Propos } \\
\text { ed }\end{array}$ & BBO & PSO \\
\hline \multirow{5}{*}{ Type 1 } & Switc & $7-32-30$ & $32-30-$ & $2-4-$ \\
& hes & $-18-3$ & $9-11-2$ & $24-2$ \\
\cline { 2 - 5 } & Powe & 130.89 & 132.22 & 158. \\
& r loss & & 2 & 661 \\
\cline { 2 - 5 } & Bus & 30 & 20 & 17 \\
& no. & & & \\
\cline { 2 - 5 } & $\%$ of & 34 & 37.34 & 24.8 \\
& loss & & & 1 \\
\hline \multirow{5}{*}{ Type 2 } & Switc & $26-2-16$ & $27-32-$ & $3-4-$ \\
& h & $-22-17$ & $23-30-$ & $10-2$ \\
\cline { 2 - 5 } & Powe & 135.48 & 140.91 & 161. \\
& r loss & & 0 & 965 \\
\cline { 2 - 5 } & Bus & 10 & 11 & 22 \\
& no. & & & \\
\hline
\end{tabular}

Coming from the above dining tables, it appears that through taking advantage of the scenario 1 and also scenario 2 , the foundation instance energy reduction (KW) in the platform is actually 211, which is actually reduced to 146.12 , 141.18. For instances 1 to 2, the price energy reduction declines are actually 26.53, 28 and also 31.14 similarly. The fee energy reduction lowering for instances 1 to 2 of a same method, therefore the lighting and also considerable tons problems are actually 24.68, 26 and also 34; 27.05, 30 as well as 31 alike. By doing this, along with various approaches, as an example, the BBO as well as PSO, the energy reduction achieved due to the innovative technique for all the lots ailments is actually evaluated. Through lessening reduction to 138.97 as versus the associate techniques (BBO-- 158.661; PSO - 174.801) at significant tons problems it is actually uncovered that the recommended strategy has actually displayed its own digestive tracts. 


\section{A BBO/PSO based Hybrid Technique for Distribution System Feeder Reconfiguration}

Furthermore, in hookup to various other techniques at sizable bunch health conditions, the amount of electrical power loss decline in the grow older creating method is actually monitored to become a fabulous 24.68 (BBO-24.81; PSO-17.16)

\section{CONCLUSION}

This paper details a common approach for situating the ability of DG in electrical power unit. In the suggested strategy, the superior place as well as capability of the DG is actually originally figured out by utilizing BBO, after that the BBO input criteria are actually identified in to the below specifications and also enabled as the PSO input. By utilizing the below criteria the PSO locates the ideal area as well as ability of DG. The absolute best end results were actually taken one of the procedures. This procedure is actually examined in the IEEE thirty-three transportation spin distribution structure as well as the efficiency is actually assessed along with the BBO formula. Listed here the contrast gets the branched circulation device electrical power reduction, current at several problems like regular disorder, throughout the error opportunity, BBO method as well as suggested shared procedure. Coming from the contrast leads our experts settled that the suggested procedure is actually the effectively efficient approach to determine the maximum area and also ability of the DG for the branched circulation body, which is actually proficient over the various other methods.

\section{REFERENCES}

1. A. Kavousi-Fard, T. Niknam and M. Fotuhi-Firuzabad, "A Nove Stochastic Framework Based on Cloud Theory and \$theta \$ -Modified Bat Algorithm to Solve the Distribution Feeder Reconfiguration," in IEEE Transactions on Smart Grid, vol. 7, no. 2, pp. 740-750, March 2016.

2. F. Ding and K. A. Loparo, "Feeder Reconfiguration for Unbalanced Distribution Systems With Distributed Generation: A Hierarchical Decentralized Approach," in IEEE Transactions on Power Systems, vol. 31, no. 2, pp. 1633-1642, March 2016.

3. S. Huang, Q. Wu, L. Cheng and Z. Liu, "Optimal Reconfiguration-Based Dynamic Tariff for Congestion Management and Line Loss Reduction in Distribution Networks," in IEEE Transactions on Smart Grid, vol. 7, no. 3, pp. 1295-1303, May 2016.

4. R. A. Jabr, I. Džafić and I. Huseinagić, "Real Time Optimal Reconfiguration of Multiphase Active Distribution Networks," in IEEE Transactions on Smart Grid, vol. 9, no. 6, pp. 6829-6839, Nov. 2018

5. M. Amin Heidari, "Optimal network reconfiguration in distribution system for loss reduction and voltage-profile improvement using hybrid algorithm of PSO and ACO," in CIRED - Open Access Proceedings Journal, vol. 2017, no. 1, pp. 2458-2461, 102017.

6. J. Singh and R. Tiwari, "Real power loss minimisation of smart grid with electric vehicles using distribution feeder reconfiguration," in IET Generation, Transmission \& Distribution, vol. 13, no. 18, pp. 4249-4261, 1792019.

7. S. Ganesh and R. Kanimozhi, "Meta-heuristic technique for network reconfiguration in distribution system with photovoltaic and D-STATCOM," in IET Generation, Transmission \& Distribution, vol. 12, no. 20, pp. 4524-4535, 13112018.

8. S. Chen, W. Hu and Z. Chen, "Comprehensive Cost Minimization in Distribution Networks Using Segmented-Time Feeder Reconfiguration and Reactive Power Control of Distributed Generators," in IEEE Transactions on Power Systems, vol. 31, no. 2, pp. 983-993, March 2016.

9. J. Wen, Y. Tan, L. Jiang and K. Lei, "Dynamic reconfiguration of distribution networks considering the real-time topology variation," in IET Generation, Transmission \& Distribution, vol. 12, no. 7, pp. 1509-1517, 1042018.
10. A. Tyagi, A. Verma and P. R. Bijwe, "Reconfiguration for loadability limit enhancement of distribution systems," in IET Generation, Transmission \& Distribution, vol. 12, no. 1, pp. 88-93, 212018.

\section{AUTHORS PROFILE}

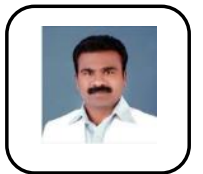

Kothuri Ramakrishna completed his Bachelor of Engineering (B.E.) in Department of EEE from Gulbarga University in the year 1998 and Master of Technology (M.Tech.) in Power Engineering from J.N.T.U Hyderabad in 2001. He also completed Master of Business Administration (MBA) in HR from Annamalai University in 2013. Presently, he is pursuing Ph.D from J.N.T.U. Hyderabad Telangana, India. He has around 19 years of teaching experience. He is working as Associate professor in B. V. Raju Institute of Technology, Narsapur, Medak district of Telangana from 2008. He worked as Associate Professor in Vardhamaan Engineering College from 2005 to 2008. He worked as Assistant Professor in Adams Engineering College Palvancha, Khammam District of Telangana 1998 to 2005.In His research interest includes, Electrical Distribution Systems, Power System Analysis. He has published several National and International Journals and Conferences. He have Professional Society memberships in IEEE (M), IETE (M), ISTE (LM),FIE (AM), SESI (LM), IAENG (M), NIQR (M), SSI (LM), SPE (LM), IAENG (LM), IACSIT (LM), and C.Eng. Presently he is counselor of IEEE student branch, Counselor for PEES(IEEE)of BVRIT, Narsapur, Medak district Telangana.

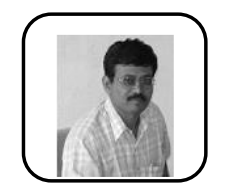

Dr. Basavaraja Banakara BE, ME, MBA (HR), PhD (NITW), Senior Member EEE, LMISTE, He obtained his Doctoral degree from National Institute of Technology, Warangal, India. He is having 25 years teaching experience in engineering college at Lecturer, Associate Professor, and Professor, \& Principal level. Presently he is working as Professor \& Chairman, Dept. of EEE, University of BDT Engineering College (Constituent College of Visvesvaraya Technological University), Davanagere, Karnataka, India. His areas of interest include power electronics and drives, Utilization of Electrical Engineering, High voltage Engineering and EMTP applications. Presented 30 publications in national \& international journals as well as in conferences. 